\title{
COMPARASION OF NDBI AND NDVI AS INDICATORS OF SURFACE URBAN HEAT ISLAND EFFECT IN LANDSAT 8 IMAGERY: A CASE STUDY OF IASI
}

\author{
Paul Macarof ${ }^{1}$, Florian Statescu $^{2}$
}

Key words: NDBI, NDVI, Land surface temperature, Surface urban heat island, Landsat-8

\begin{abstract}
This study compares the normalized difference built-up index (NDBI) and normalized difference vegetation index (NDVI) as indicators of surface urban heat island effects in Landsat- 8 OLI imagery by investigating the relationships between the land surface temperature (LST), NDBI and NDVI. The urban heat island (UHI) represents the phenomenon of higher atmospheric and surface temperatures occurring in urban area or metropolitan area than in the surrounding rural areas due to urbanization. With the development of remote sensing technology, it has become an important approach to urban heat island research. Landsat data were used to estimate the LST, NDBI and NDVI from four seasons for Iasi municipality area. This paper indicates than there is a strong linear relationship between LST and NDBI, whereas the relationship between LST and NDVI varies by season. This paper suggests, NDBI is an accurate indicator of surface UHI effects and can be used as a complementary metric to the traditionally applied NDVI.
\end{abstract}

\section{Introduction}

The urban heat island (UHI) represents the phenomenon of higher atmospheric and surface temperatures occurring in urban area or metropolitan area than in the surrounding rural areas due to urbanization (Voogt and Oke, 2005). UHI is most noticeable during the summer and winter. The main cause of the UHI effect is from the modification of land surfaces(Solecki et al., 2005). Waste heat

${ }^{1} \mathrm{PhD}$ student Eng., „Gheorghe Asachi” Technical University of Iasi, Faculty of Hydrotechnical Engineering, Geodesy and Environmental Engineering, e-mail lates.iustina90@ gmail.com

${ }^{2}$ Professor Dr. Eng., Gheorghe Asachi”'Technical University of Iasi, Faculty of Hydrotechnical Engineering, Geodesy and Environmental Engineering, e-mail mluca2004@yahoo.com 
generated by energy usage is a secondary contributor ( $\mathrm{Li}$, Zhao, 2012). With the rising of these urban or metropolitan environment issues, scientists have paid more attention on UHI research. Therefore, how to monitor, analyze, and evaluate the urban heat island effect quantitatively has become one of the prime important research among current urban climate and environment studies.

With the development of remote sensing technology, it has become an important approach to urban heat island research. In earlier thermal remote sensing studies, much emphasis has been placed on using NDVI as the major indicator of urban climate, and results indicate there is a linear relationship between Land surface temperature and NDVI, this negative correlation between them is valuable for urban climate studies (Carlson et al., 1994). For all that, NDVI measurements are subject to seasonal variations which may influence the results of surface urban heat island studies. Furthermore, the relationship between LST and NDVI is well known to be nonlinear. Thus, NDVI alone may not be a sufficient metric to study SUHI quantitatively. According to studies the relationship between LST and percent impervious surface area (ISA) by using Landsat TM and ETM+ data in an urbanized environment, they found that percent ISA was an accurate indicator of surface UHI effects with strong linear relationships between LST and percent ISA for all the four seasons (Yuan et al., 2011). The normalized difference build-up index (NDBI) represents one of the major land cover types, that is, build-up areas (Zha, Gao and Ni, 2005). Moreover, like NDVI, NDBI is very simple and easy to obtain, so it is feasible to use NDBI to substitute for percent impervious surface area for study of surface urban heat island. NDBI can be used as indicator of intensity of development and as indicator of urban impervious surface.

\section{DATA AND METHODS}

\subsection{Study area}

Iasi is the largest city in eastern Romania and the seat of Iasi County. Located in the historical region of Moldavia, Iasi has traditionally been one of the leading centers of Romanian social, cultural, academic and artistic life. The city is positioned on the Bahlui River, affluent of Jijia that flows into the Prut River, Iasi is the "legendary city of the seven hills", namely Cetățiia, Galata, Copou, Bucium, Şorogari, Repedea and Breazu, just like so many cities around world, one such example being Rome. Some of these hills have conspicuous churches perched on top, each of which warrants a different view of the city. The local climate is continental with minimal rainfall and with large temperature differences between the seasons. Summer is hot and it lasts from the end of the month of May up to the half of September. Autumn is a short season, of transition. In the second half of November there is usually frost and snow. Winter is a freezing season with 
temperatures dropping to $-20{ }^{\circ} \mathrm{C}$ (https://en.wikivoyage.org/wiki/Iași). Study Area is geographically situated on latitude $47^{\circ} 12^{\prime} \mathrm{N}$ to $47^{\circ} 06^{\prime} \mathrm{N}$ and longitude $27^{\circ} 32^{\prime} \mathrm{E}$ to $27^{\circ} 40^{\prime} \mathrm{E}$.

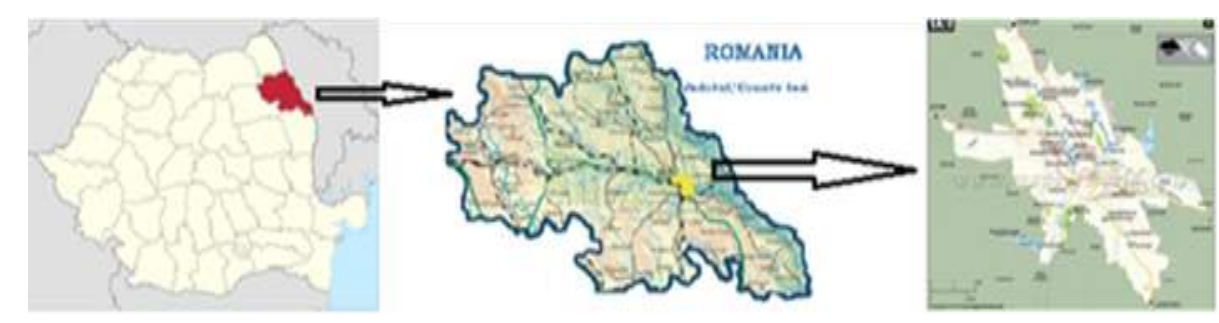

Fig.8.Study Area (wikipedia, rotravel)

\subsection{Landsat data}

The main objective of this study was to compare the relationships of LST to NDBI and NDVI using Landsat data obtained from four different seasons using Iasi metropolitan area as a case study.

Landsat 8 measures different ranges of frequencies along the electromagnetic spectrum - a color, although not necessarily a color visible to the human eye. Each range is called a band, and Landsat 8 has 11 bands. Bands 10 and 11 are in the thermal infrared, or TIR - they see heat. Instead of measuring the temperature of the air, like weather stations do, they report on the ground itself, which is often much hotter (NASA Landsat Science)

Table 1. Landsat data

\begin{tabular}{|c|c|c|c|}
\hline Nr. Crt. & Path & Row & Date \\
\hline 1 & 182 & 27 & $2016-02-11$ \\
\hline 2 & 182 & 27 & $2016-05-01$ \\
\hline 3 & 182 & 27 & $2016-08-05$ \\
\hline 4 & 182 & 27 & $2016-11-09$ \\
\hline
\end{tabular}

\subsection{Data processing}

The Normalized Difference Vegetation Index (NDVI) is a numerical indicator that uses the visible and near-infrared bands of the electromagnetic spectrum, and is adopted to analyze remote sensing measurements and assess whether the target being observed contains live green vegetation or not (John Rouse, 1973). The NDVI algorithm subtracts the red reflectance values from the near-infrared and divides it by the sum of near-infrared and red bands.

$$
\mathrm{NDVI}=\frac{N I R-R E D}{N I R+R E D}
$$


NDBI in next equation is a normalized difference built-up index which is used to extract built-up area, first it was used for TM data by Zha, Y., Gao, J. and $\mathrm{Ni}, \mathrm{S}$. in 2003.

$$
\mathrm{NDBI}=\frac{S W I R_{1}-N I R}{S W I R_{1}+N I R}
$$

\section{RESLUTS AND DISCUSSION}

\subsection{LST, NDBI and NDVI spatial patterns}

LST (land surface temperature) is used to determine the temperature distribution at the change global, regional and local scale. At the same time, it is used in climate and acclimate change models in particular. LST, calculated from remote sensing data is used in a lot of sphere of science, like: agriculture, climate change, hydrology, forestry, urban planning, oceanography etc. Obtaining surface temperatures and using them in different analysis is important to determine the problem associated with the environment (Orhan et al. 2014).

The LST maps are presents in Figure 2.
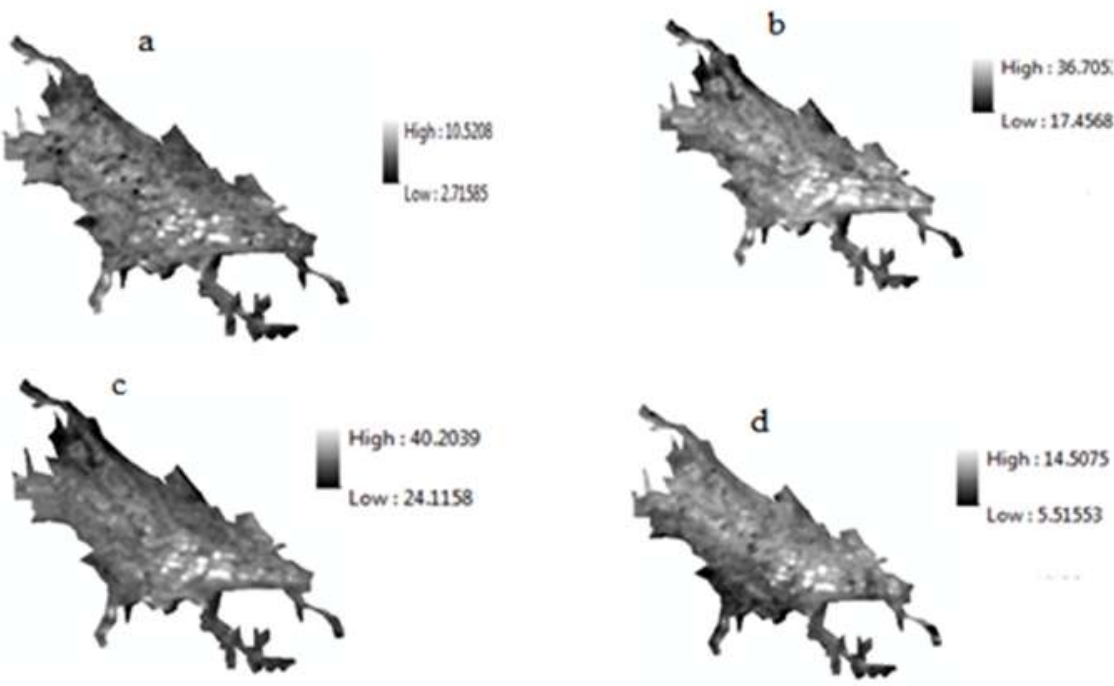

Fig.9. LST maps for four seasons (a-2016-02-11; b-2016-05-01; c-2016-08-08; d-2016-11-09) 
Table 2.Statistical data of LST for four seasons $\left({ }^{\circ} \mathrm{C}\right)$

\begin{tabular}{|c|c|c|c|c|c|}
\hline Seasons & Minimum & Maximum & Variations & Mean & $\begin{array}{c}\text { Standard } \\
\text { Deviation }\end{array}$ \\
\hline Winter & 2.71 & 10.52 & 7.81 & 5.48 & 0.79 \\
\hline Spring & 17.46 & 36.71 & 19.25 & 23.99 & 2.24 \\
\hline Summer & 24.12 & 40.20 & 16.09 & 29.86 & 1.94 \\
\hline Autumn & 5.52 & 14.51 & 8.99 & 9.89 & 0.81 \\
\hline
\end{tabular}

NDBI statistical data for the four dates are shown in Table 3. The variations of NDBI are higher summer and spring than smaller winter and autumn.

The NDBI maps are presents in Figure 3. The NDBI in bulit-up area of summer and spring are obviously higher than winter and autumn.

Table 3. Statistical data of NDBI

\begin{tabular}{|c|c|c|c|c|c|}
\hline Seasons & Minimum & Maximum & Variations & Mean & $\begin{array}{c}\text { Standard } \\
\text { Deviation }\end{array}$ \\
\hline Winter & -0.22 & 0.38 & 0.60 & 0.02 & 0.029 \\
\hline Spring & -0.38 & 0.32 & 0.70 & 0.10 & 0.089 \\
\hline Summer & -0.38 & 0.42 & 0.80 & 0.07 & 0.076 \\
\hline Autumn & -0.23 & 0.41 & 0.64 & 0.01 & 0.026 \\
\hline
\end{tabular}
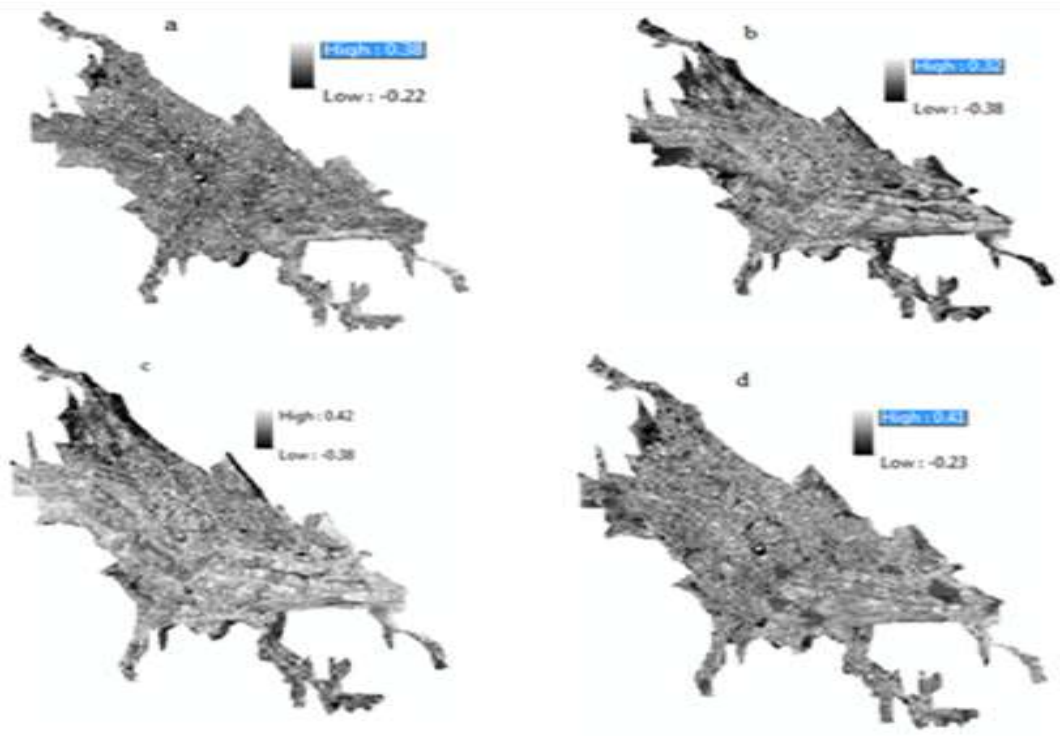

Fig.10. NDBI maps for four dates (a-winter, b-spring, c-summer, d-autumn) 
As can be seen from Table 3 and Figure 3, the NDBI values for four seasons are quite close, these indicate NDBI varies less with the season.

NDVI maps and statistical data for the four dates are shown in Fig. 4 and Tab. 4
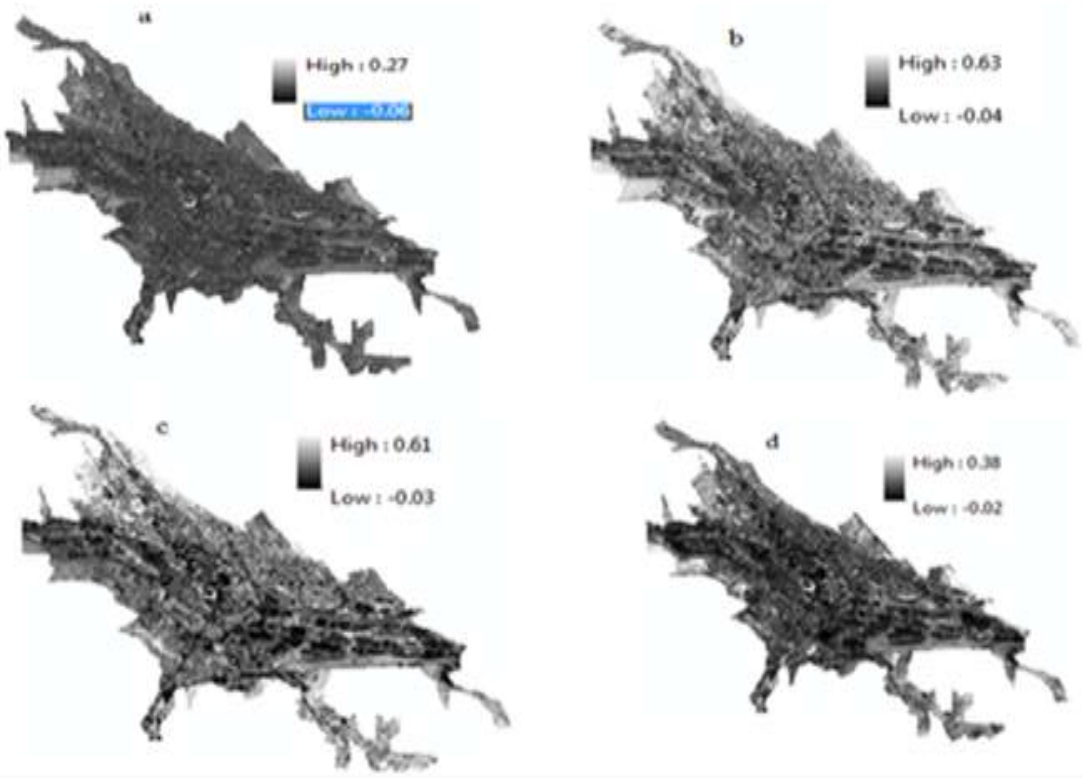

Fig.11. NDVI maps for four dates (a-winter, b-spring, c-summer, d-autumn)

Table 4. Statistical data of NDVI

\begin{tabular}{|c|c|c|c|c|c|}
\hline Seasons & Minimum & Maximum & Variations & Mean & $\begin{array}{c}\text { Standard } \\
\text { Deviation }\end{array}$ \\
\hline Winter & -0.06 & 0.27 & 0.33 & 0.05 & 0.03 \\
\hline Spring & -0.04 & 0.63 & 0.66 & 0.26 & 0.12 \\
\hline Summer & -0.03 & 0.61 & 0.64 & 0.22 & 0.11 \\
\hline Autumn & -0.02 & 0.38 & 0.40 & 0.09 & 0.05 \\
\hline
\end{tabular}

The parameters: variations, mean and standard deviations of NDVI for four seasons showing that this index are higher spring and summer than autumn and winter when all the vegetation was defoliated. The variations for spring and summer are over 0.6 while for autumn and winter are about 0.3-0.4. The mean for May-August is about 0.2-0.3 while for November-February is $0.05-0.1$. These all indicate NDVI has evident seasonal change which is exactly different to NDBI. 


\subsection{LST relationships to NDBI and NDVI}

Figure 7 indicates consistent linear patterns between LST and NDBI for all the seasons, while in Figure 8 the relationship between LST and NDVI is nonlinear and strongly affected by season.

Research over the past two decades has shown that the surface radiant temperature response is determined by both surface soil water content and vegetation cover (Goetz, 1994; Price, 1990). The variation in the pixel temperatures may be mostly related to built-up site amounts and characteristics since vegetated surfaces vary less in temperature than urban surfaces. Moreover, NDBI is sensitive to the build-up area.

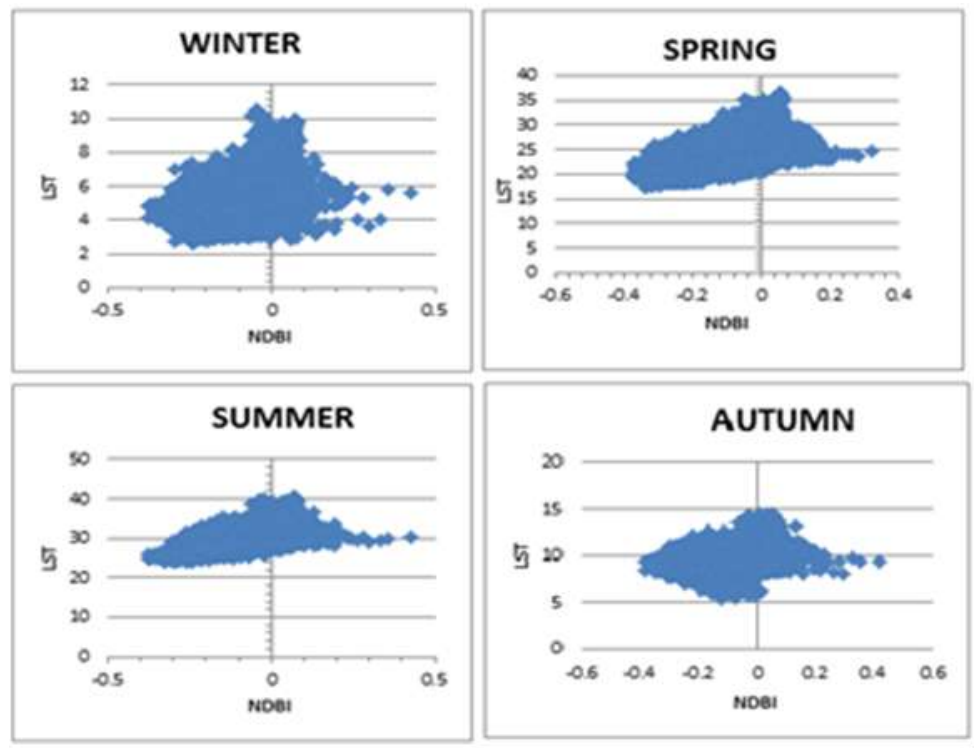

Fig.12. Scatter plots of NDBI and LST for four dates

Irregular patterns with NDVI values are shown in the scatter plots for the autumn and winter data. These results suggest that although NDVI may be used for analysis of surface UHI effects during spring and summer, NDBI is suitable for LST studies for all the seasons across our study area (Gillies, R. R., Carlson, T. N., Cui, J., et al., 1997). 

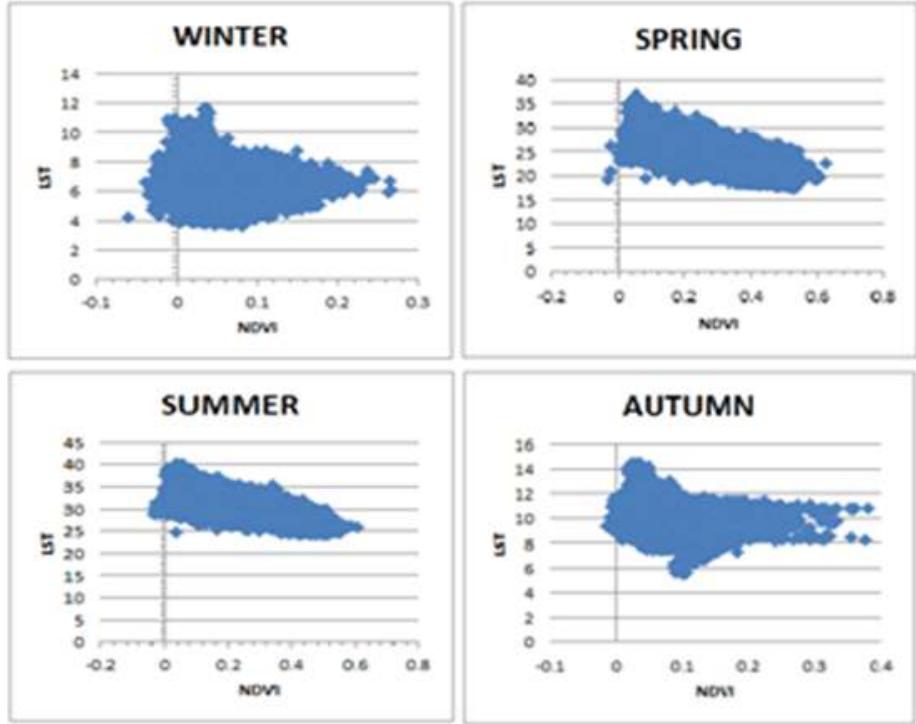

Fig. 6. Scatter plots of NDVI and LST for four dates
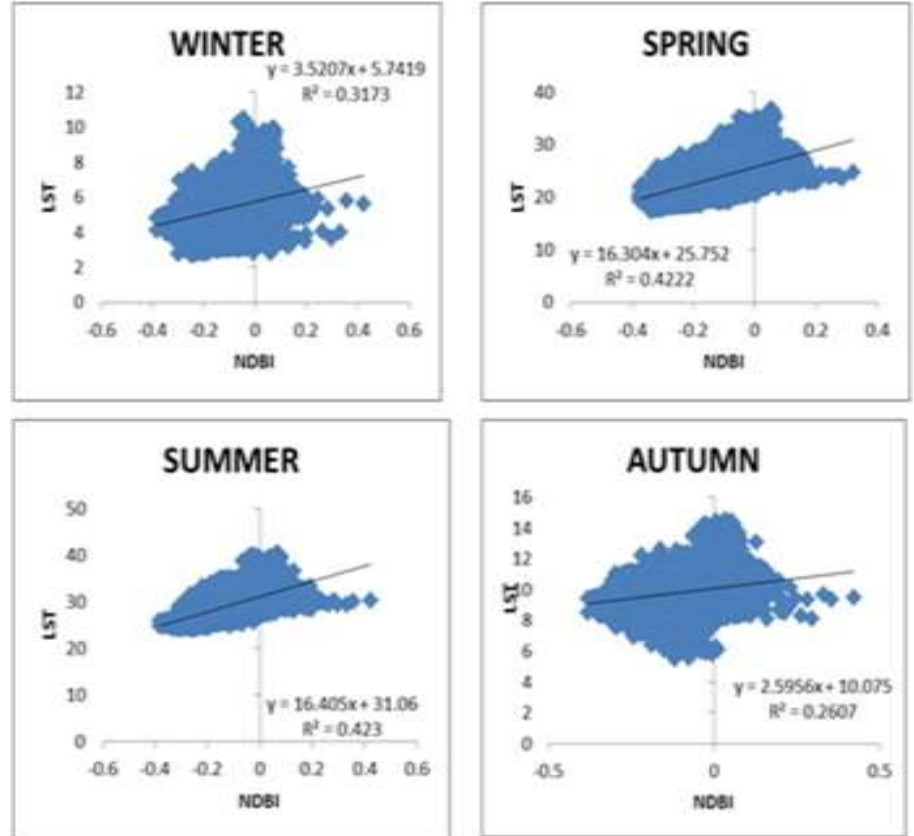

Fig. 7. Relationship of NDBI and LST for four dates 

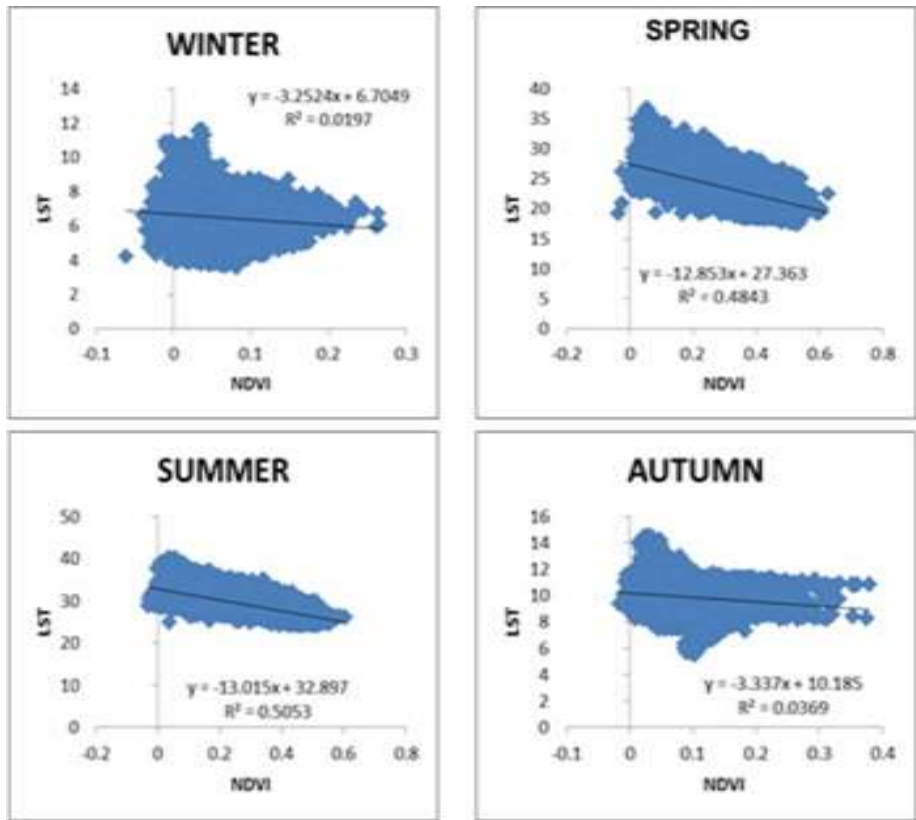

Fig.13. Relationship of NDVI and LST for four dates

\section{Conclusions}

This paper investigated the relationships between the LST, NDBI and NDVI in Iasi. Results indicate there is a strong linear relationship between LST and NDBI for all the four date, whereas the relationship between LST and NDVI varies by season. The linear relationship between the LST and NDBI suggests that urban zone accounts for most of the variation in land surface temperature dynamics. Therefore, NDBI is an accurate indicator of surface UHI effects and can be used as a complementary metric to the traditionally applied NDVI.

\section{References}

Carlson T. N., Gillies R. R., Perry E. M., A method to make use of thermal infrared temperature and NDVI measurements to infer surface soil water content and fractional vegetation cover, 1994

Chen X.-L., Zhao H.-M., Li P.X., Yin, Z.-Y, Remote sensing image-based analysis of the relationship between urban heat island and land use/cover changes, 2006

Dihkan M., Karsli F., Guneroglu, A., Guneroglu N., Evaluation of surface urban heat island (SUHI) effect on coastal zone: The case of Istanbul Megacity

Fabrizi R., Bonafoni S.; Biondi R., Satellite and Ground-Based Sensors for the Urban Heat Island Analysis in the City of Rome, 2010 
Gillies R. R., Carlson T. N., Cui J., A verification of the 'triangle' method for obtaining surface soil water content and energy fluxes from remote measurements of the normalized difference vegetation index, NDVI and surface temperature, International Journal of Remote Sensing, 1997

Goetz S. J., Multi-sensor analysis of NDVI, surface temperature and biophysical variables at a mixed grassland site, 1997

Imhoff M. L., Zhang, P., Wolfe R. E., Bounoua L., Remote sensing of the urban heat island effect across biomes in the continental USA, 2010

Kriegler F. J., Malila W. A., Nalepka R. F., Richardson W., Preprocessing transformations and their effects on multispectral recognition. In Remote Sensing of Environment, 1969

Liu K., Su H., Zhang L., Yang H., Zhang R., Li X., Analysis of the Urban Heat Island Effect in Shijiazhuang, China Using Satellite and Airborne Data, 2015

Ogashawara I., Bastos V., Quantitative Approach for Analyzing the Relationship between Urban Heat Islands and Land Cover, 2012

Orhan O., Ekercin S., Dadaser-Celik F., Use of Landsat Land Surface Temperature and Vegetation Indices for Monitoring Drought in the Salt Lake Basin Area, 2014

Price J. C., Using spatial context in satellite data to infer regional scale evapotranspiration, 1990

Purevdorj T. S., Tateishi R., Ishiyama T., Relationships between percent vegetation cover and vegetation indices, 1998

Rouse J. W., Haas R. H., and Schell J. A., Monitoring the vernal advancement and retrogradation (greenwave effect) of natural vegetation, Texas A and M University, College Station, 1974

Streutker D. R., A remote sensing study of the urban heat island of Houston, Texas, 2002.

Voogt J. A. and Oke T. R., Thermal remote sensing of urban climates, 2003

Weng Q. H., Lu D. S., Schubring J., Estimation of land surface-vegetation abundance relationship for Urban Heat Island studies, 2004

Xian G.; Crane M., An analysis of urban thermal characteristics and associated land cover in Tampa Bay and Las Vegas using Landsat satellite data, 2006

Xiong Y., Huang, S., Chen F., Ye H., Wang C., Zhu C., The Impacts of Rapid Urbanization on the Thermal Environment, 2012

Yuan F. and Bauer M. E., Comparison of impervious surface area and normalized difference vegetation index as indicators of surface Urban Heat Island effects in Landsat Imagery, 2007

Zha Y., Gao J. and Ni S., Use of normalized difference built-up index in automatically mapping urban areas from TM imagery, 2003

Zha Y., Gao J., Ni S., Use of normalized difference built-up index in automatically mapping urban areas from TM imagery, 2003

Zhao H., Chen X., Use of normalized difference bareness index in quickly mapping bare areas from TM/ETM, 2005

* https://en.wikivoyage.org/wiki/Iași

**https://en.wikipedia.org/wiki/Iași 